\title{
СПЕЦИФИКА ОБУЧЕНИЯ ГРАМОТЕ ДЕТЕЙ С ТЯЖЕЛЫМИ НАРУШЕНИЯМИ РЕЧИ
}

\author{
Богатая Ольга Федоровна \\ старший научный сотрудник \\ БУ ВО «Сургутский государственный \\ педагогический университет»
}

\begin{abstract}
Аннотация: тенденция к увеличению численности детей $\mathrm{c}$ нарушениями речи, неготовность к обучению грамоте детерминируют необходимость поиска, разработки и реализации эффективных методов обучения. В статье представлена авторская методика обучения грамоте детей с речевой патологией, сущность которой заключается в организации обучения чтению детей с тяжелыми нарушениями речи в соответствии с последовательностью формирования правильного звукопроизношения и возможностями речепорождающего механизма детей. Данная методика в течение 10 лет апробирована в образовательных учреждениях г. Сургута и разных территориях ХМАО - Югры. Результаты апробации позволили сделать вывод, что обучение грамоте детей с тяжелыми нарушениями речи с учетом речевого онтогенеза способствует успешному овладению детьми чтением и письмом.
\end{abstract}

Ключевые слова: дети с тяжелыми нарушениями речи, учебнометодический комплект, онтогенез, дифференциация и автоматизация звуков, инновационные аспекты обучения грамоте, взаимодействие речеслухового и речепорождающего механизма у детей с речевой патологией.

\section{THE SPECIFICS OF TEACHING CHILDREN TO READ AND WRITE WITH SEVERE SPEECH DISORDERS}

\section{Bogataya Olga Fedorovna}

\begin{abstract}
: the tendency towards an increase in the number of children with speech disorders, the unavailability to learn to read and write determine the need to search, develop and implement effective teaching methods. The article presents the author's method of teaching literacy to children with speech pathology, the essence of which is to organize reading instruction for children with severe speech disorders
\end{abstract}


in accordance with the sequence of formation of correct sound pronunciation and the capabilities of the speech-generating mechanism of children. This technique has been tested in educational institutions for 10 years . Surgut and various territories of KHMAO - Yugra. The results of the approbation allowed us to conclude that teaching literacy to children with severe speech disorders, taking into account speech ontogenesis, contributes to the successful mastery of reading and writing by children.

Key words: children with severe speech disorders, educational and methodological kit, ontogenesis, differentiation and automation of sounds, innovative aspects of literacy teaching, interaction of the speech-hearing and speech-generating mechanism in children with speech pathology.

В настоящее время отмечается устойчивая тенденция к увеличению численности детей дошкольного возраста с речевыми нарушениями. У многих детей отмечается системное недоразвитие всех сторон устной речи, они испытывают значительные трудности при формировании представлений о языковых единицах и специфике их функционирования: фонемах, лексемах, грамматических формах и конструкциях, закономерностях реализации высказываний. При поступлении в школу неполноценность устной речи детей с речевой патологией проявляется в сложностях овладения письменной речью, обусловленных недостаточной сформированностью предпосылок к усвоению звукового анализа: обучающиеся затрудняются или не могут выделить звуки из анализируемого слова; смешивают звук с акустически парным; затрудняются в определении звукового состава слов, отличающихся одним звуком. Поэтому на письме и при чтении преобладают фонологические замены.

В существующих в настоящее время учебниках по обучению грамоте буквы изучаются в следующей последовательности: А, О, И, Ы, У, Н, С, К, Т, Л, Р, В, Е, П, М, 3, Б, Д, Я, Г, Ч, Ь, Ш, Ж, Ё, И, Х, Ю, Ц, Э, Щ, Ф, Ъ. что зачастую не соответствует произносительным способностям обучающихся, так как у большинства из них имеются нарушения звукопроизношения, а также это противоречит требованиям к обучению чтению детей с тяжелыми нарушениями речи (далее - ТНР), предполагающим, что усвоение правильного произношения звуков всегда должно предшествовать изучению соответствующих букв и последовательность изучения букв должна осуществляться от правильно произносимых звуков раннего онтогенеза к звукам, наиболее трудным по артикуляции. Чтение текстов, содержащих дефектно произносимые детьми звуки, способствуют закреплению неправильного звукопроизношения, снижению уровня усвоения материала и мотивации к чтению. Неготовность детей с ТНР к 
обучению грамоте обусловила необходимость разработки и внедрения инновационных подходов обучения детей с речевой патологией.

Учитывая особенности формирования звукопроизношения и фонематического восприятия у детей с ТНР, специфику усвоения детьми звукобуквенного состава слов, трудности формирования лексикограмматических категорий и связной речи разработан учебно-методический комплект, состоящий из учебного пособия «Обучение грамоте», являющегося учебником для формирования навыков чтения у детей с ТНР; рабочей программы учебного предмета по обучению грамоте для первого иИили первого дополнительного класса общеобразовательных организаций, реализующих адаптированную основную общеобразовательную программу начального общего образования (далее - АООП НОО) обучающихся с ТНР; методических рекомендаций по использованию учебного пособия «Обучение грамоте» и тетрадей-прописей, предназначенных для добукварного и букварного периодов обучения. Учебно-методический комплект «Обучение грамоте» разработан в соответствии с требованиями ФГОС $\mathrm{HOO}$ обучающихся с ограниченными возможностями здоровья и примерной АООП HOO обучающихся с ТНР, одобренной решением федерального учебнометодического объединения по общему образованию (рис. 1).
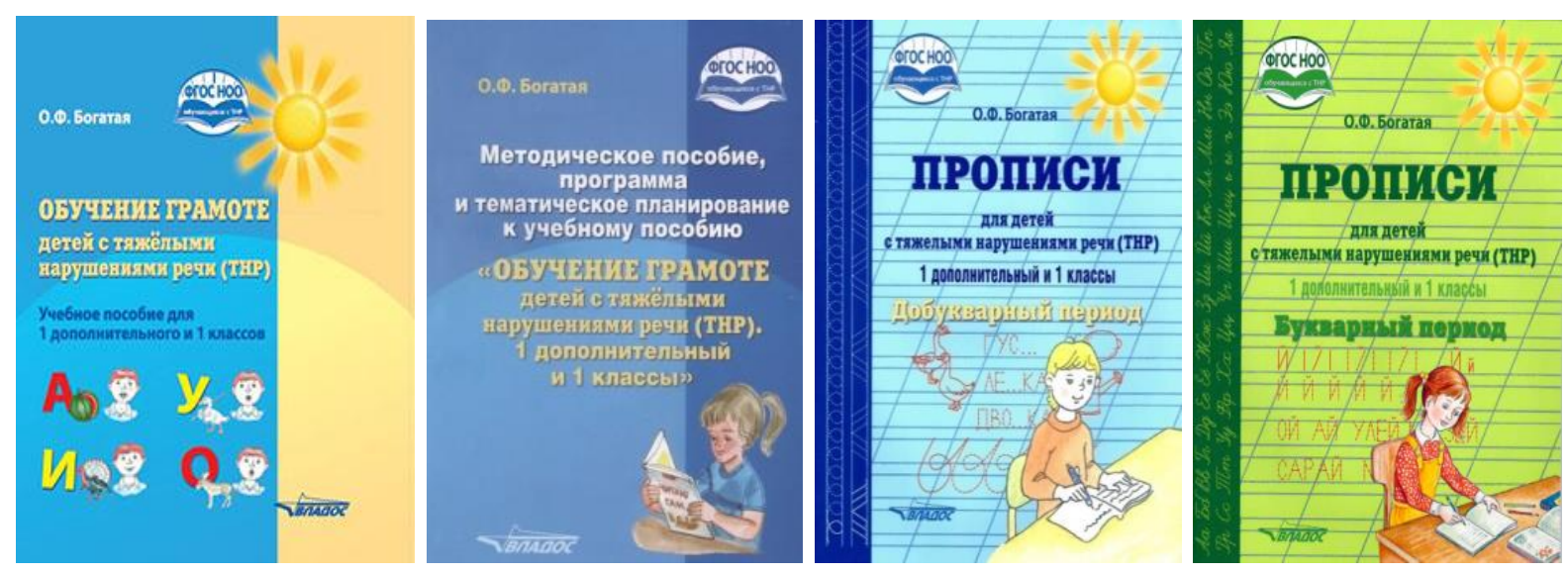

\section{Рис. 1. Учебно-методический комплект}

Преимущественным отличием книги «Обучение грамоте» от имеющихся на сегодняшний день учебников по обучению грамоте является учет особенностей становления речевого онтогенеза, специфики функционирования и взаимодействия речеслухового и речепорождающего механизма у детей с речевой патологией. Изучение букв по данной книге 
осуществляется с учетом последовательности формирования звукопроизношения у ребенка в онтогенезе. В первый год жизни ребенок произносит самые простые по артикуляции однозвучные гласные звуки [а], [о], [и], [у], [э], [ы] и согласные [м], [п], [б]. Из этих звуков состоят первые слова: мама, папа, баба. Затем ребенок произносит артикуляторно простые согласные звуки, не требующие сложных движений губ и языка: [ф], [в], [т],

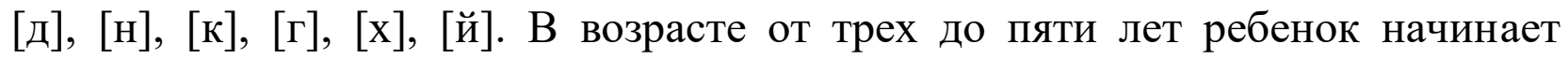
произносить более сложные по артикуляции согласные звуки: [c], [3], [ц], [ш], [ж], [ч], [щ]. К пяти годам нормотипичный ребенок правильно произносит самые сложные звуки позднего онтогенеза [л], [р]. В пять-шесть лет он осваивает правильное произношение всех звуков родного языка.

Учитывая, что у многих детей имеются нарушения произношения свистящих, шипящих, сонорных звуков; несформированность фонематики, лексики и грамматики, в рабочей программе и в книге «Обучение грамоте» предлагается следующая последовательность изучения звуков и букв: Аа, Уу, Ии, Оо, Ээ, ы, Мм, Пп, Бб, Тт, Дд, Нн, Вв, Фф, Кк, Гг, Хх, Йй, Яя, Ее, Ёё, Юю, Сс, Зз, Цц, Шш, Жж, Чч, Щщ, ь, ъ, Лл, Рр. Данный порядок изучения букв положен в основу разработки текстового и иллюстративного материала книги «Обучение грамоте» и соответствует основным требованиям к обучению детей с тяжелыми нарушениями речи, регламентирующим, что усвоение правильного произношения звуков предшествует изучению соответствующих букв.

Обучение грамоте основывается на аналитико-синтетическом звукобуквенном методе в сочетании с логопедическими технологиями закрепления навыков правильного произношения, автоматизации и дифференциации звуков. Обучение начинается с букв, обозначающих однозвучные гласные звуки. Детей знакомят с буквой, обозначающей гласный звук [а]. На странице книги дети рассматривают рукописные (прописную и строчную) буквы $\mathbf{A}, \mathbf{a}$; сравнивают рукописные и печатные буквы; прописывают буквы $\mathbf{A}, \mathbf{a}$ в тетради-прописи. Аналогично первоклассников знакомят с буквой У. После того, как обучающиеся научились соотносить звук с соответствующим ему знаком (буквой), их обучают слитному чтению. Для этого на странице книги «Обучение грамоте» дети рассматривают как буквы «идут» друг к другу; длительно озвучивают первую букву слога двигая пальцем по стрелочке «идут» к другой букве $(\mathbf{a} \rightarrow \mathbf{y}, \mathbf{y} \rightarrow \mathbf{a})$, озвучивают вторую букву, произносят - читают слоги «ау», «уа». Так дети учат пять букв, обозначающих гласные звуки, усваивают понятие «слог», составляют и читают слоги. Далее они изучают буквы, обозначающие согласные звуки 
раннего онтогенеза. При изучении букв, обозначающих согласные звуки, дети должны называть их без призвука гласной, то есть «п», «в», «з», а не «пэ», «Вэ», «३ээ».

Для закрепления характеристики звука и графического образа буквы введены условные обозначения изучаемых букв: красный цвет - для букв, обозначающих гласные звуки; зелёный - для букв, обозначающих мягкие согласные звуки; синий - для букв, обозначающих твёрдые согласные звуки. Наглядно изображены особенности артикуляции однозвучных гласных звуков положение губ). Над буквами, обозначающими звонкие согласные звуки, находится колокольчик (рис. 2).

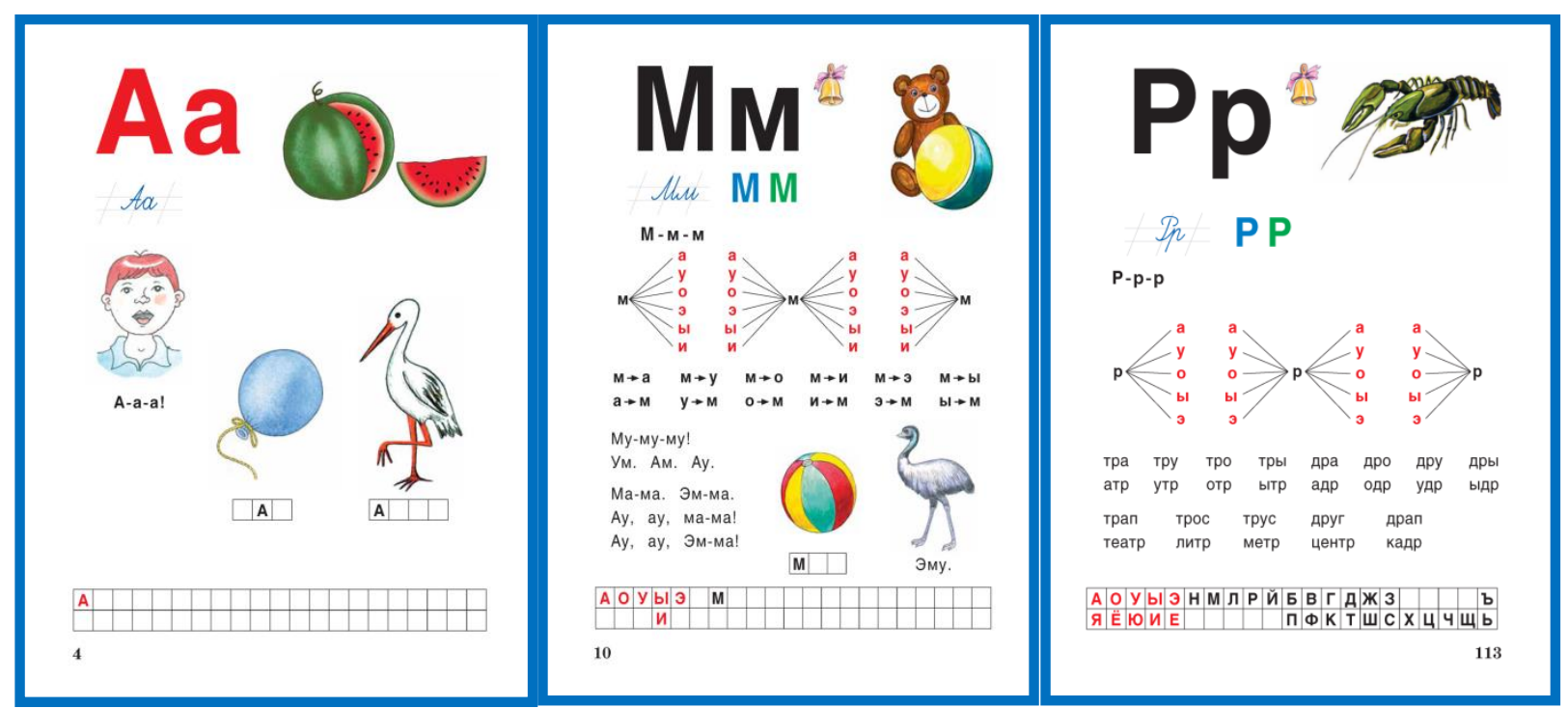

Рис. 2. Страницы книги «Обучение грамоте»

При знакомстве с новой буквой в конце страницы книги «Обучение грамоте» помещаются таблицы, в которых каждая буква располагается в соответствии с характеристикой обозначаемого звука: на верхней полосе буквы, обозначающие гласные звуки первого ряда [a, у, ы, о, э] и буквы, обозначающие звонкие согласные звуки [н, м, л, р, й, б, в, г, д, ж, з]; на нижней полосе - буквы, обозначающие гласные второго ряда [я, ё, ю, и, е] и буквы, обозначающие глухие согласные звуки [п, ф, к, т, ш, с, х, ц, ч, щ]. При этом парные глухие согласные располагаются под звонкими согласными, а под непарными звонкими согласными и над непарными глухими согласными остаются пустые клетки. По мере изучения букв обучающиеся заполняют аналогичную таблицу, расположенную во второй части Прописей (табл. 1). 
Таблица 1

Таблица букв

\begin{tabular}{|c|c|c|c|c|c|c|c|c|c|c|c|c|c|c|c|c|c|c|c|c|}
\hline $\mathbf{A}$ & $\mathbf{y}$ & Ы & O & Э & $\mathbf{M}$ & Б & Д & $\mathbf{H}$ & B & $\Gamma$ & & Й & 3 & & Ж & & & $\boldsymbol{I}$ & $\mathbf{P}$ & $\mathbf{b}$ \\
\hline Я & Ю & И & $\ddot{\mathrm{E}}$ & $\mathbf{E}$ & & $\Pi$ & $T$ & & $\Phi$ & $\mathbf{K}$ & $\mathbf{X}$ & & $\bar{C}$ & Ц & I & $\overline{4}$ & $\mathrm{JU}$ & & & \\
\hline
\end{tabular}

На внутренней стороне обложки книги «Обучение грамоте» изображён Замок букв $u$ звуков, в котором буквы располагаются в соответствии с обозначающими их звуками. Детям объясняют, что на крыше замка «живут» самые главные буквы, обозначающие гласные звуки; буквы, обозначающие согласные звуки живут в башнях. В башне с самым большим колокольчиком «живут» буквы, обозначающие самые звонкие (сонорные) согласные звуки. В башне с маленьким колокольчиком «живут» буквы, обозначающие звонкие согласные звуки. На третьей и четвёртой башенках нет колокольчика, только «язычок». В этих башнях «живут» буквы, обозначающие глухие согласные звуки (рис. 3).

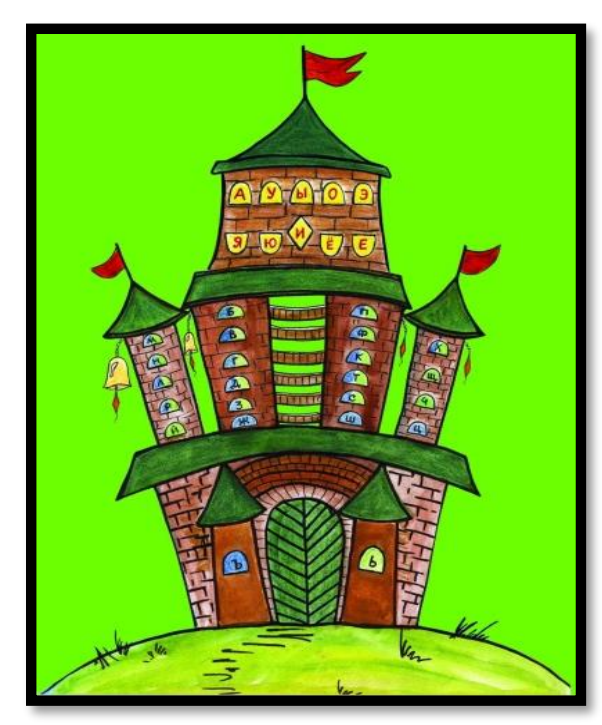

\section{Рис. 3. Замок букв и звуков}

Между второй и третьей башнями есть мостик. Он соединяет буквы, обозначающие похожие по звучанию звуки. Это парные звуки. Если буква из башни с колокольчиком «перейдёт» в башню без колокольчика - она из буквы, обозначающей звонкий согласный звук, «превратиться» в букву, обозначающую глухой согласный звук. И наоборот. Окошечки, в которых располагаются буквы, могут быть синего, зеленого или сине-зеленого цвета в соответствии с твердостью или мягкостью согласных звуков. 
При знакомстве с новой буквой обучающиеся определяют место буквы в Замке букв и звуков.

Наиболее важным этапом при первоначальном обучении детей чтению является овладение чтением прямого слога. Для отработки чтения слогов детям предлагаются схемы, где каждая буква, обозначающая согласный звук, дается в сочетании со всеми ранее изученными буквами, обозначающими гласные звуки: прямые и обратные слоги; слоги, в которых согласный звук находится в интервокальном положении (табл. 2).

Таблица 2

\section{Таблица слогов}

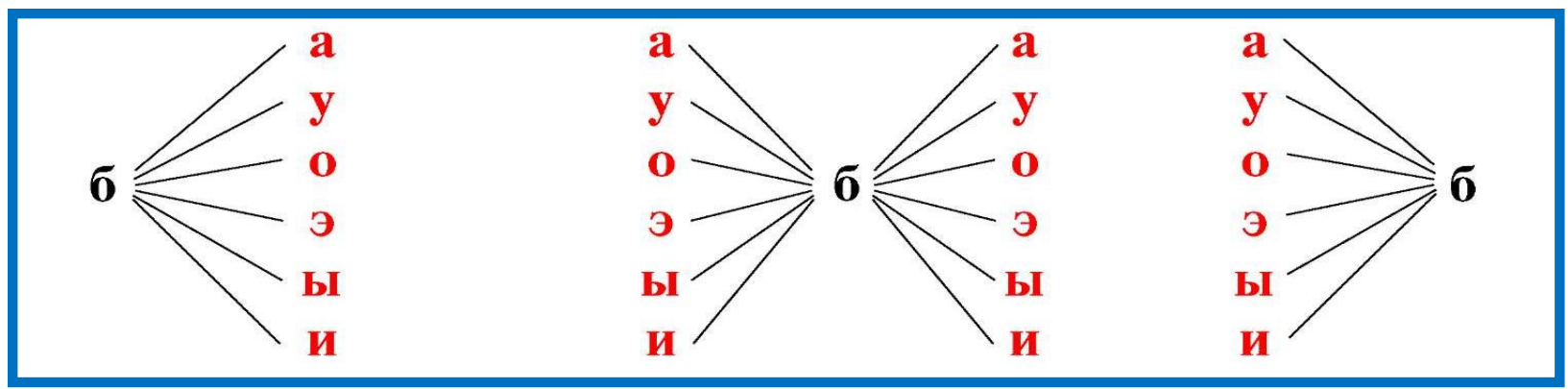

Далее предлагаются слоги со стечением согласных, что соответствует позиционному принципу. В процессе упражнений у ребёнка формируется обобщенный образ слога, который необходим для узнавания слога при чтении слов. После усвоения послогового чтения, детям предлагается чтение слов, расположенных в столбиках. Чтобы чтение было плавным, слова в столбиках строятся по принципу наращивания. При чтении слов дети узнают, что звуки в словах располагаются в определенном порядке и изменение количества или последовательности звуков в слове может привести к изменению смысла слова. Они наблюдают слово в слове, учатся находить родственные слова, изменять слова по числам, родам и падежам. Параллельно с формированием умения делить слова на слоги, обучающиеся усваивают правила переноса слов.

Формирование навыков связной речи начинают с чтения коротких предложений и простых по содержанию текстов. Чтобы прочитать предложение ребенку необходимо осмыслить каждое слово. Для понимания смысла прочитанной фразы, взгляд ребенка при чтении останавливается на каждом читаемом слове и вновь возвращается назад - к прочитанному слову, что позволяет ему не утратить взаимосвязь читаемого слова со словом, прочитанным ранее. У обучающихся с нарушениями речи очень медленный 
темп чтения, поэтому они зачастую не узнают в тексте знакомые слова и простые словосочетания, новую форму слова дети могут воспринимать как неизвестное слово. Поэтому при обучении чтению значительное время необходимо отводить работе по наращиванию скорости чтения слогов, плавному слоговому чтению слов, а также чтению целыми словами словосочетаний, предложений и коротких текстов, предложенных в книге «Обучение грамоте». Содержание текстов для чтения и структура предложений постепенно усложняются, включаются сложносочиненные и сложноподчиненные предложения, простые диалоги, вопросительные предложения; предложения с обращением. Работа по увеличению скорости чтения проводится при чтении диалогов, чистоговорок, стихотворений, скороговорок. Это способствует усвоению навыков плавного, сознательного и выразительного слогового чтения и навыков чтения целыми словами с элементами слогового чтения сложных слов. У первоклассников возрастает темп чтения, они начинают осваивать синтетический способ чтения, однако понимание читаемого отстает во времени от зрительного восприятия слова. Показателями освоения синтетического чтения являются: правильное, беглое, выразительное и осознанное чтение.

Одновременно с обучением чтению первоклассников обучают письму. В процессе письма происходит взаимодействие четырех анализаторных систем: речеслуховой; речедвигательной, зрительной и двигательной. Трудности освоения процесса письма у детей с тяжелыми нарушениями речи обусловлены необходимостью перевода фонем (звуков) в графемы - в зрительные схемы графических знаков (буквы). Ребенку необходимо запомнить пространственное расположение элементов букв, затем осуществить «перешифровку» зрительных образов букв в кинетическую систему и последовательно выполнить движения, необходимые для записи определенной буквы. При этом ребенку следует проводить анализ печатного и письменного образа буквы, графических знаков, из которых состоит каждая буква; осуществлять сопоставление букв, содержащих сходные элементы. Навыки письма дети закрепляют в тетрадях-прописях для добукварного и букварного периода (рис. 4). 

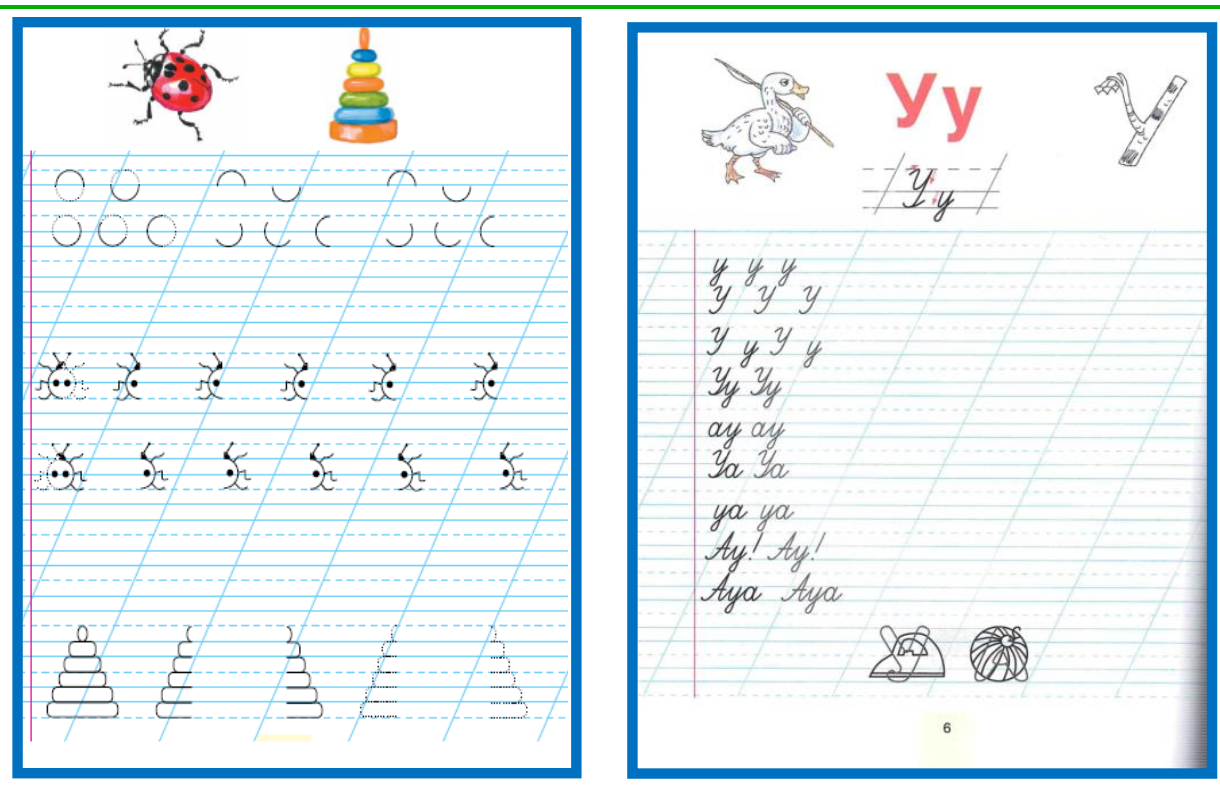

Рис. 4. Страницы тетрадей-прописей

Учитывая полифункциональность анализаторов, необходимых для усвоения чтения, в книге «Обучение грамоте» предлагается разнообразный практический материал для развития психомоторных функций, оптикопространственных и временных представлений. Система коррекционноразвивающих упражнений разработана в соответствии с психологическими особенностями и возможностями детей, представлена в игровой форме и включает задания, способствующие возникновению интегративных связей: слухоречевых, двигательно-кинестетических и оптико-пространственных. Взаимодействие деятельности речезрительного, речедвигательного, речеслухового, кинестетического анализаторов актуализирует ассоциативные связи в коре головного мозга, необходимые для успешного усвоения системы букв. Оптимально подобранные коррекционно-развивающие упражнения на последовательно усложняющемся речевом материале (слогах, словах и фразах), направленные на развитие высших психических функций, пространственных и временных представлений, связной речи детей, способствуют формированию прочных звукобуквенных связей, необходимых для овладения письмом. Для предупреждения нарушений письма подобран материал на дифференциацию звуков сходных по твёрдости и мягкости, звонкости и глухости: [п-б, п-П, б-б, т-Д, вc-ш, щ-c-3, Л-p] и т. д.

Обучающиеся усваивают правила орфографии, грамматики и пунктуации: заглавная буква; знаки препинания знаки; правила переноса слов, 
правописание словарных слов; сочетаний «ши», «жи», «ча», «ща», «чу», «щу» и другие.

Важным является то, что при знакомстве с новой буквой и обучению чтению на странице книги «Обучение грамоте» нет ни одной незнакомой детям буквы, все дополнительные задания (реши ребус, прочитай слово справа налево и наоборот, произноси скороговорку быстро и др.) предлагаются в виде схем. Форма изложения материала оказывает благотворное влияние на выработку оптимального темпа и ритма речи, способствует воспитанию сознательного отношения к чтению, формированию интереса к стихам, поэзии, русской речи.

Программа учебного предмета «Обучение грамоте» обучающихся с THP состоит из целевого, содержательного и организационного разделов, составленных в соответствии с требованиями к АООП НОО обучающихся с THP.

В методических рекомендациях содержится теоретический и практический материал по использованию книги «Обучение грамоте» $u$ рабочей программы учебного предмета по обучению грамоте детей с ТНР.

Методика по обучению грамоте в виде методического пособия по закреплению произносительных навыков и чтения у детей с нарушениями речи «Читалочка» была представлена родителям, воспитывающим детей с речевой патологией. С 2007 года она прошла успешную апробацию в подготовительных к школе логопедических группах детских садов, в первых классах школ разных территорий ХМАО-Югры. Результаты катамнеза позволили констатировать, что дети, обучавшиеся чтению по пособию «Читалочка», успешно усваивали программу по обучению грамоте в общеобразовательных школах.

Материал учебно-методического комплекта «Обучение грамоте», созданный на основе методического пособия «Читалочка» значительно расширен, составлен в соответствии с ФГОС НОО обучающихся с ТНР.

Таким образом, обучение детей с ТНР с использованием учебнометодического комплекта «Обучение грамоте», разработанного в соответствии с развитием фонетико-фонематической системы ребенка в онтогенезе, способствует закреплению правильного звукопроизношения, развитию фонематического слуха, формированию навыков чтения, активизации познавательной деятельности. Обучение чтению с опорой на правильное произношение повышает уверенность ребенка в своих силах, 
развивает интерес к чтению, способствует более качественному усвоению знаний, формированию коммуникативной функции речи, преодолению страха речи, негативизма, повышению мотивации к обучению, препятствует школьной дезадаптации.

Учебно-методический комплект можно использовать для обучения детей, не имеющих нарушений речи. Доступность, последовательность и системность материала позволит родителям обучать ребенка чтению самостоятельно. Учебно-методический комплект «Обучение грамоте» могут использовать учителя начальных классов, студенты-дефектологи специальной педагогики.

\section{Список литературы}

1. Богатая О. Обучение грамоте детей с тяжелыми нарушениями речи 1 дополнительный и 1 классы. Учебное пособие для общеобразовательных организаций, реализующих ФГОС НОО обучающихся с ТНР по вариантам 5.1. и 5.2. / О.Ф. Богатая, - М., ООО Издательство Владос, 2018. - 128 с. : ил.

2. Богатая О. Методическое пособие, программа и тематическое планирование к учебному пособию Обучение грамоте детей с тяжелыми нарушениями речи 1 дополнительный и 1 классы. / О.Ф. Богатая, - М., ООО Издательство Владос, 2018. - 150 с.

3. Богатая О. Читалочка: Методическое пособие по закреплению произносительных навыков и чтения у детей с нарушениями речи / Богатая О.Ф. - М., Международный журнал прикладных и фундаментальных исследований: ИД «Академия естествознания». - 2013 - № 2. - С. 123-124.

4. Каше Г.А. Подготовка к школе детей с недостатками речи: Пособие для логопеда. - М.: Просвещение, 1985. - 207 с.

(C) О.Ф. Богатая, 2022 